Delft University of Technology

\title{
Two-way Augmented Reality Co-location Under Telemedicine Context
}

Li, Meng; Slijkhuis, Tom ; Huigen, Remko; Albayrak, Armagan; van Eijk, Daan

DOI

10.1109/ISMAR-Adjunct54149.2021.00121

Publication date

2021

Document Version

Accepted author manuscript

Published in

Proceedings - 2021 IEEE International Symposium on Mixed and Augmented Reality Adjunct, ISMAR-

Adjunct 2021

\section{Citation (APA)}

Li, M., Slijkhuis, T., Huigen, R., Albayrak, A., \& van Eijk, D. (2021). Two-way Augmented Reality Co-location Under Telemedicine Context. In L. O'Conner (Ed.), Proceedings - 2021 IEEE International Symposium on Mixed and Augmented Reality Adjunct, ISMAR-Adjunct 2021: Proceedings (pp. 504-505). [9585828]

(Proceedings - 2021 IEEE International Symposium on Mixed and Augmented Reality Adjunct, ISMARAdjunct 2021). IEEE . https://doi.org/10.1109/ISMAR-Adjunct54149.2021.00121

Important note

To cite this publication, please use the final published version (if applicable).

Please check the document version above.

\footnotetext{
Copyright

Other than for strictly personal use, it is not permitted to download, forward or distribute the text or part of it, without the consent of the author(s) and/or copyright holder(s), unless the work is under an open content license such as Creative Commons.

Takedown policy

Please contact us and provide details if you believe this document breaches copyrights.

We will remove access to the work immediately and investigate your claim.
} 


\section{Two-way Augmented Reality Co-location Under Telemedicine Context}

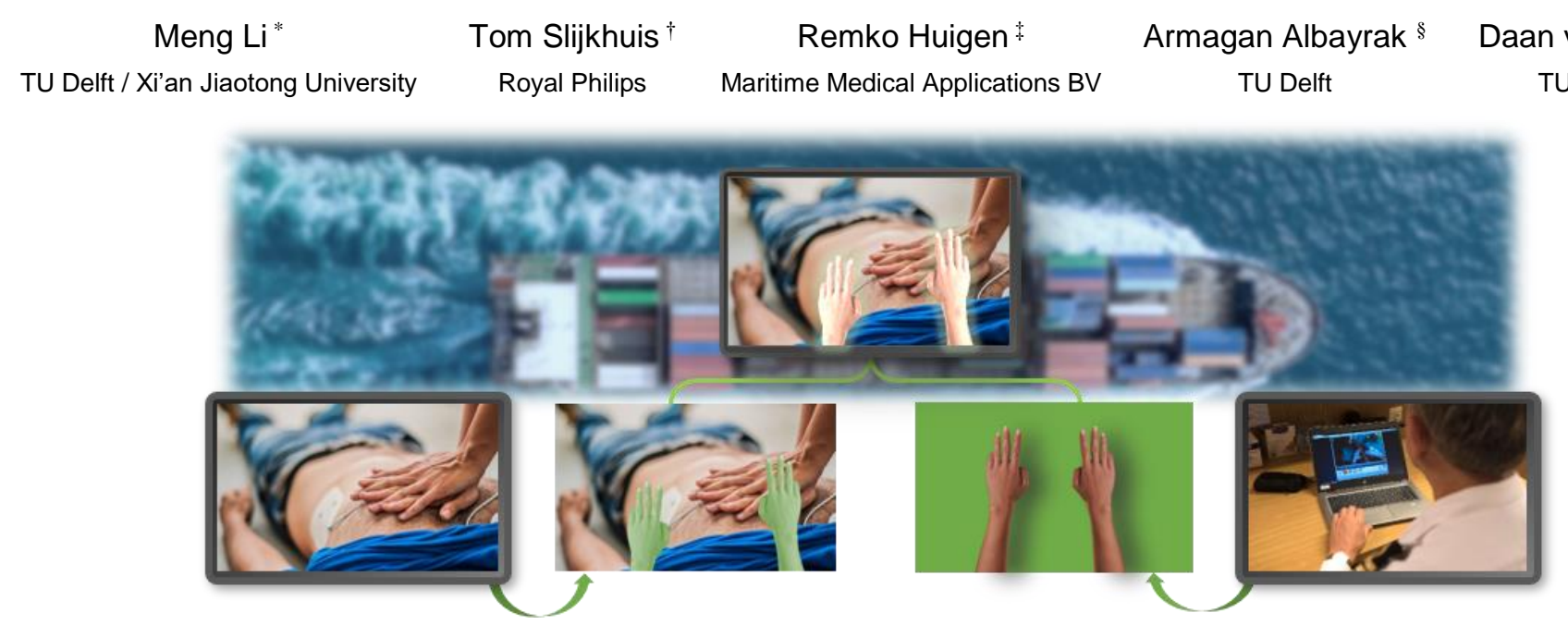

Figure 1: Two-way AR service concept in marine medical care

\begin{abstract}
The medical care responsibilities are often on the shoulders of nonprofessionals such as captains who are equipped with forty hours of designated training every five years. However, this training is neither enough for the captains to handle medical incidents nor releases their stress during the treatment. Currently, captains have very limited support from a medical expert, only via phone call or email from the Radio Medical Services. Thus, the authors explored that how the two-way augmented reality (AR) can support the collaboration between captains and doctors for a better quality of care. A Human-Centred Design approach is applied in this study, including field study and user testing. The lean user experience method was applied with fast prototyping-testing loops. The main findings are AR played an essential role to boost confidence on the captain's side, and the real value of AR is in supporting medical skills like suturing and abdominal searching. This study serves as a pilot research, thus it was limited by small sample size and qualitative method. Improving the communication between the captains and doctors is key for future studies.
\end{abstract}

Keywords: Collaborative augmented reality, co-location, telemedicine, remote expert, Human-centered computing.

Index Terms: H.5.1 [Information Systems]: INFORMATION INTERFACES AND PRESENTATION - Multimedia Information Systems; H.5.2 [Information Systems]: INFORMATION INTERFACES AND PRESENTATION - user interface; J.3 [Computer Applications]: LIFE AND MEDICAL SCIENCES

\section{INTRODUCTION}

As International Maritime Organization (IMO) emphasizes, medical care is a substantial part of the onboard safety operation [1]. Doctors are only available for large commercial vessels with

*email: m.li-4@tudelft.nl; †email: t.slijkhuis18@gmail.com

†email: r.huigen@medassist.online; ${ }^{\S}$ email: A.Albayrak@tudelft.nl

Iemail: D.J.vanEijk@tudelft.nl more than a hundred crews, so medical training of seafarers is of paramount importance. Despite the emphasis on medical care and safety, the first aid and medical training for officers (captains and first mates) are only forty hours every five years [2]. The limited amount of training neither equipping enough skills to handle onboard medical care independently nor releasing stress when handles first aid. Mobile training apps thus were applied to facilitate onboard medical training. However, captains and first mates still need guidance to cope with complex and urgent situations under time pressure, like open injuries and first aids.

Augmented Reality (AR) techniques are used to support such context-related information exchange [3]. The co-location, which provides a shared virtual space, is the key characteristic of AR to enable this information exchange [4]. In a review of AR usability studies from 2004 to 2015, Dey and his team found twelve studies focused on collaborative AR and forty-three on medical AR [6]. Among them, only three AR collaboration studies were performed under true-to-life setups, and one study on medical VR applications used handhold-based AR. The mainstream of AR-based collaboration involves remote connection, asymmetric tasks, and synchronous responses, and focuses on remote expert involvement $[4,6]$.

Handhold-based AR (e.g. smartphones or tablets) has low development and implementation thresholds than headsets, thus the industry shows higher interest in it. Pilot studies of handhold-based AR applications that promote collaborative medical care however are very rare. The goal of this study is to develop and test a twoway AR service concept using a tablet to bring remote medical experts to locations wherever and whenever they are needed (Figure 1). To achieve this goal, we will focus on the following research question:

How to develop two-way AR services on handholds to support telemedical treatments?

\section{Method}

In this study, the human-centered design is applied in a set of pilot studies from local-remote AR collaboration with Lego models, to defining the workspace from the doctor's side, and finally compared two set-ups from both captain and doctor sides [6]. In a pre-study, the custom journey mapping was used to discover user's needs and the potential AR services. The Minimum Viable Product (MVP) of 
two-way AR services was implemented on iPads or Samsung tablet computers [7]. All participants took part in the studies voluntarily and informed consents were collected before each test.

\subsection{Study One: 2-Way AR Collaboration}

Two captains participated in this pilot study to investigate where to place the camera to share context-related information better: from the tablet or on glasses. They both played the roles of captain and remote doctor to build two Lego models together via a prototype of the AR service. In condition 1, the captain used a tablet to both share the view and get visual and vocal instruction from the doctor; in condition 2, the captain used a camera on glasses and received only visual instructions from the tablet. Doctors used their hands and/or voice to guide the captain via the second tablet. A predefined questionnaire with a seven-point Liker scale was used to collect feedback, where " 1 " for "fully disagree" and "7" for "fully agree". In the end, researchers asked open questions concerning how easy was the experience, their likes or dislikes, and how smooth was the communication.

\subsection{Study Two: 2-way AR workspace}

The main requirement for the doctor was to control the oversized virtual hands to give accurate instruction. The authors thus defined a $50 \mathrm{~cm}$ envelope as a doctor's workspace according to the $50^{\text {th }}$ percentile arm length of the Dutch gender-mixed population. Four combinations of the height and angle of the tablet support $(0 \mathrm{~cm} 10$ $\circ, 10 \mathrm{~cm} 20^{\circ}, 20 \mathrm{~cm} 30^{\circ}$, and $25 \mathrm{~cm} 30^{\circ}$ )were tested. Five participants with a height from 170 to $182 \mathrm{~cm}$ (two female and three male at average age 34) joined in the test and matched their virtual hands with sample images on an AR app. Their task load was measured and analyzed via NASA-TLX (twenty-point scale) and the task duration was recorded [8]. In the end, a set of open questions were asked to collect qualitative feedback regarding comfort and accuracy.

\subsection{Study Three: 2-way AR Full Set-up}

The study compared two set-ups (Figure 2) of AR telemedicine services that simulated an on-board medical treatment. Six captains (one female and five males with average age 38.2) and two doctors from Radio Medical Services took part in this test. Each team of captain and doctor needed to perform with both set-ups. Four captains had medical care training, one trained with basic safety and one had no relevant training. The task loads on both sides were measured via NASA-TLX[8]. The following behaviours were observed: mutual communication, mutual understanding, ease-ofuse, performance, understanding of the situation (doctor), and understanding of instructions (captain).

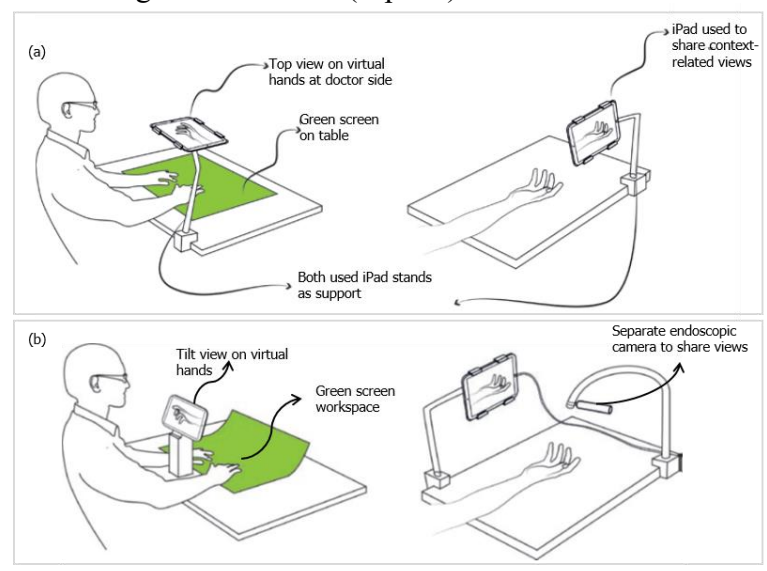

Figure 2: Set-up 1 (a) and Set-up 2 (b).

\section{RESULtS}

Sharing the first-person view of the captain plus vocal instruction and (hand) pointing was effective in communicating contextrelated information between the local worker--the captain, and the remote expert - the doctor. However, the remote expert needed a stable view to check the overall. Hence, a flexible, while fixable camera tethered to a tablet is of value to serve the goal.

Controlling the virtual objects, e.g. virtual hands, from the remote expert side is critical to provide accurate guidance. Hence, a suitable workspace needs to be taken into consideration as well as the AR app itself.

The adjustable cameras and tablet supports showed their importance in reducing task loads and durations, which are critical resources to handle emergencies. Environmental factors such as light play important roles in using tablet-based AR apps, especially under safety-critical scenarios such as telemedical treatment in the marine sector.

There are the following limitations of this study that opens new rooms for future studies on collaborative AR in healthcare: 1) the sample sizes of pilot studies were very small due to the limited population of a cargo ship captain and the doctors of radio medical services. Further studies should test their setup with broader using context in telemedicine. 2) The 2D hands were helpful but still limited with their functionalities, more tools are needed to show different types of actions. 3) The doctors reported the virtual hands as larger than in real life, which needs in-depth investigation on the influencing factors of their perception.

\section{Conclusion}

Two-way AR has low development and implementation cost as major advantages, and sharing the first-person view with vocal communication and visual pointers can share context-related information effectively. A human-centered design combining with minimum viable products probed the user's needs in-depth, then confirmed them in fast "design-test" loops, which ensures the AR services concepts fulfil potential user's requirements and needs.

\section{ACKNOWLEDGMENTS}

Meng Li thanks China Scholarship Council to sponser her dcotoral research (No. 201706280020).

\section{REFERENCES}

[1] IMO. About IMO. Retrieved October 27, 2018, from http://www.imo.org/en/About/Pages/Default.aspx

[2] Sekimizu, K., 2010. STCW a Guide for Seafarers. International Transport Workers' Federation.

[3] Lukosch, S., Lukosch, H., Datcu, D. and Cidota, M., 2015. Providing information on the spot: Using augmented reality for situational awareness in the security domain. Computer Supported Cooperative Work (CSCW), 24(6), pp.613-664.

[4] Ens, B., Lanir, J., Tang, A., Bateman, S., Lee, G., Piumsomboon, T. and Billinghurst, M., 2019. Revisiting collaboration through mixed reality: The evolution of groupware. International Journal of HumanComputer Studies, 131, pp.81-98.

[5] Dey, A., Billinghurst, M., Lindeman, R.W. and Swan, J., 2018. A systematic review of 10 years of augmented reality usability studies: 2005 to 2014. Frontiers in Robotics and AI, 5, p.37.

[6] Desmet, P. and Fokkinga, S., 2020. Beyond Maslow's pyramid: introducing a typology of thirteen fundamental needs for humancentered design. Multimodal Technologies and Interaction, 4(3), p.38.

[7] Gothelf, J., 2013. Lean UX: Applying lean principles to improve user experience. " O'Reilly Media, Inc."

[8] Rubio, S., Díaz, E., Martín, J. and Puente, J.M., 2004. Evaluation of subjective mental workload: A comparison of SWAT, NASA-TLX, and workload profile methods. Applied psychology, 53(1), pp.61-86. 